\title{
Effects of Home-Based Physical Exercise on Days at Home and Cost-Effectiveness in Pre-Frail and Frail Persons : Randomized Controlled Trial
}

\section{Suikkanen, Sara A.}

2021-04

Suikkanen, S A , Soukkio , P K, Aartolahti , E M , Kautiainen , H , Kääriä , S , Hupli , M T , Sipilä , S , Pitkälä , K \& Kukkonen- Harjula , K 2021, ' Effects of Home-Based Physical Exercise on Days at Home and Cost-Effectiveness in Pre-Frail and Frail Persons :

Randomized Controlled Trial ' , Journal of the American Medical Directors Association , vol. 22 , no. 4 , pp. 773-779 . https://doi.org/10.1016/j.jamda.2020.06.005

http://hdl.handle.net/10138/332479

https://doi.org/10.1016/j.jamda.2020.06.005

cc_by_nc_nd

acceptedVersion

Downloaded from Helda, University of Helsinki institutional repository.

This is an electronic reprint of the original article.

This reprint may differ from the original in pagination and typographic detail.

Please cite the original version. 
1 Effects of home-based physical exercise on days at home and cost-effectiveness in pre-

2 frail and frail persons - RCT

3 Sara A. Suikkanen ${ }^{a, b}$ MSc

4 Paula K. Soukkio ${ }^{a, b}$ MSc

5 Eeva M. Aartolahti ${ }^{\text {b }} \mathrm{PhD}$

6 Hannu Kautiainen ${ }^{\mathrm{C}}$ BA

7 Sanna M. Kääriä ${ }^{d} \mathrm{PhD}$

8 Markku T. Huplia MD, PhD

9 Sarianna Sipiläb,e PhD

Kaisu H. Pitkäläc MD, PhD

Katriina T. Kukkonen-Harjula ${ }^{\mathrm{a}} \mathrm{MD}, \mathrm{PhD}$

12

aRehabilitation, South Karelia Social and Health Care District, Lappeenranta, FINLAND

14 bFaculty of Sport and Health Sciences, University of Jyväskylä, Jyväskylä, FINLAND

cUnit of Primary Health Care, University of Helsinki, Department of General Practice, and

Helsinki University Hospital, Helsinki, FINLAND

${ }^{\mathrm{d}}$ Raatimiehet Oy, Lappeenranta, FINLAND

'e Gerontology Research Center, Faculty of Sport and Health Sciences, University of Jyväskylä, Jyväskylä, FINLAND

Corresponding author:

Sara Suikkanen

South Karelia Social and Health Care District, Lappeenranta, Finland 
Postal address: Valto Käkelän katu 3, FI-53130, Lappeenranta, Finland

e-mail: sara.suikkanen@eksote.fi

telephone: +358 406511692

Running title: Home-based physical exercise in pre-frail and frail

Key words: Frailty, exercise, cost-effectiveness, utilization of social and healthcare services

Funding: This work was supported by South Karelia Social and Health Care District (Eksote, grant register number 1236/00.01.05.01/2013); the Social Insurance Institution of Finland (SII, register number 94/331/2013); and State Research Funding for Academic Health Research (Ministry of Social Affairs and Health, Finland). The funders had no role in the design, nor in collection, analysis and interpretation of the data, nor in writing the manuscript.

Word, reference and graphics count: Abstract words: 299, main text words: 3010 references: 42 , tables/figures: 4

Running title: Days at home and cost-effectiveness of exercise

Brief Summary: Twelve-month supervised home-based exercise had no effect on days lived at home vs. usual care in cases of frailty. It prevented decline in quality-of-life. The first years' increased healthcare costs were regained over the next year. 


\section{ABSTRACT}

Objectives Frailty increases the risks of hospitalization, institutionalization and death. Our objective was to study the effects of home-based physical exercise on the number of days spent at home among pre-frail and frail persons, vs. usual care. In addition, utilization and costs of healthcare and social services, cost-effectiveness and health-related quality-of-life (HRQoL) were explored.

Design: Randomized controlled trial, with yearlong supervised exercise for 60 minutes twice a week vs. usual care. Follow-up for 24 months after randomization.

Setting and participants: A sample of 299 home-dwelling persons in South Karelia, Finland. Main inclusion criteria: $\geq 65$ years, meeting at least one of the frailty phenotype criteria, MiniMental State Examination score $\geq 17$

Methods: Primary outcome, days spent at home over 24 months, was calculated deducting days in inpatient care, in nursing homes, and days after death. HRQoL was assessed (15D questionnaire) at baseline, and at 3, 6 and 12 months. Utilization data were retrieved from medical records.

Results: The participants' mean age was 82.5 (SD 6.3), 75\% were women, $61 \%$ were pre-frail and 39\% frail. After 24 months, there was no difference between groups in days spent at home (incidence rate ratio, IRR 1.03 [95\% Cl 0.98-1.09]). After 12 months, the costs per person-year were 1.60-fold in the exercise group (95\% $\mathrm{Cl} 1.23-1.98)$, and after 24 months, 1.23 -fold ( $95 \% \mathrm{Cl} 0.95-1.50)$ vs. usual care. Over 12 months, the exercise group gained 0.04 quality-adjusted life-years and maintained the baseline 15D level, while the score in the usualcare group deteriorated ( $p$ for group $<0.001$, time 0.002 , interaction 0.004 ).

Conclusions and implications: Physical exercise did not increase the number of days spent at home. Exercise prevented deterioration of HRQoL, and in the frail subgroup, all intervention 

costs were compensated with decreased utilization of other healthcare and social services

67 over 24 months.

68

69 


\section{INTRODUCTION}

Frailty is a medical condition caused by deterioration of the physiological capacity of the organ systems, predisposing a person to stressors such as infections. ${ }^{1,2,3}$ Recovery from illnesses is slow, and the person may not recuperate to their previous functional level. ${ }^{1}$ Frailty is an extreme consequence of the normal ageing process, being multidimensional and dynamic, ${ }^{4,5}$ and is more prevalent in women than in men. ${ }^{6,7}$ Physical frailty is defined by frailty phenotype criteria, which include weight loss, weakness, low physical activity, slowness and exhaustion. ${ }^{8}$ By meeting three or more of the criteria, a person is considered as frail and by meeting one or two, as pre-frail. ${ }^{8}$

When compared with robust persons, frail persons experience more hospitalizations $s^{9,10,11,12}$ and longer stays at hospital; ${ }^{13}$ they have lower health-related quality-of-life (HRQoL) ${ }^{14}$ and a higher risk of mortality. ${ }^{2,15}$ Both frailty and pre-frailty states are predictors of nursing home placement. ${ }^{16}$ The severity of frailty is associated with greater healthcare and social services costs, as they can be 2.6 times higher for frail persons, and 1.7 times higher for pre-frail persons when compared with robust persons. ${ }^{17,18}$

Treatment of frailty is nonpharmacological, and progressive, individualized multicomponent physical exercise with resistance training is one option. ${ }^{3}$ Whether exercise regimens can decrease inpatient hospital stays and postpone nursing-home admission, and whether the period of living at home could thus be lengthened, are open questions when considering frail and pre-frail older adults. Furthermore, there is a scarcity of studies on home-based training, ${ }^{3}$ and there is inconsistent evidence on whether or not physical exercise can improve HRQoL among frail and pre-frail older adults ${ }^{19,20}$ and whether exercise interventions are costeffective. 
The primary aim of this randomized controlled trial was to study the effects of a 12-month physiotherapist-supervised home-based physical exercise program on the number of days spent at home over 24 months in pre-frail and frail persons, compared with usual care. In addition, the utilization and costs of healthcare and social services over 24 months, and HRQoL over 12 months were assessed. We also calculated quality-adjusted life-years (QALYs) and cost-effectiveness of the intervention by using incremental cost-effectiveness ratio (ICER).

\section{METHODS}

\section{Design and settings}

The methods and protocol of this randomized controlled trial have been previously presented in detail. ${ }^{21}$ Three hundred voluntary participants were recruited between December 2014 and August 2016. Prior to the start of recruitment, the study was registered at ClinicalTrials.gov (NCT02305433), and ethics approval was received in November 2014 from the relevant coordinating ethics committee. All participants signed a written informed consent document.

\section{Participants}

To be eligible, a person needed to score at least one point in the FRAIL questionnaire ${ }^{22}$ and fulfill at least one of the frailty phenotype criteria. ${ }^{8}$ Two of the phenotype criteria were slightly modified..$^{23}$ To define "low physical activity" we used 30 minutes per week as a cut-off value. For the slowness criterion, we used a common gait speed cutoff-value of $0.46 \mathrm{~m} / \mathrm{s}$ for both genders, which was based on the lowest quartile in the Short Physical Performance Battery. ${ }^{24,25}$ Participants were classified as pre-frail if they met 1-2 phenotype criteria and frail if they met $3-5$. Other eligibility criteria were: age $\geq 65$ years, home-dwelling (with or 
without homecare services), able to walk with or without aid when indoors, a Mini-Mental

State Examination (MMSE) ${ }^{26}$ score of $\geq 17$ and no severe illnesses that prevented them taking part in exercise training. Eligible persons were randomized to physical-exercise $(n=150)$ and usual-care groups ( $n=150)$. Randomization was performed after the baseline assessments in consecutive order by using a computer program with varying block sizes, without stratification.

\section{Outcomes}

The primary outcome was the number of days spent at home during the 24-month period (730 days), beginning at the date of randomization. The outcome was considered relevant as the national policy in our country is focused on supporting the older people's abilities to live at home, and postponing a possible nursing home placement. Overnight stays in hospital wards, long-term wards, nursing homes, and days after death up to the end of the two-year period were summed up, and defined as days not lived at home. Information was gathered from the medical records of the social and healthcare district, which is responsible for primary and secondary healthcare and social services.

For secondary outcomes, data on the utilization and costs of healthcare and social services were gathered and analyzed over the 24-month period starting from the day of randomization. Business intelligence (BI) analysts, blinded to allocation, retrieved information on used services from the participants' medical records. We also retrieved information from the social-insurance registers, which provided information on the number of used healthcare services in the private sector. Both datasets were merged by our statistician and included in our analyses. 
137 All contacts between the patients and professionals in healthcare and social services, days in

138 inpatient care and nursing homes, and the physiotherapy sessions of our intervention were

139 included in the analyses. Costs were calculated by multiplying the number of service-

140 utilization units by the price of each unit. National mean unit costs in 2011 were used, ${ }^{27}$ and

141 the prices were corrected to the 2018 level according the inflation rate based on the cost-of-

142 living index. For our intervention the mean cost of one physiotherapist visit (86.50€) was used

143 and multiplied by the number of completed visits, and included in the rehabilitation costs of

144 the exercise group. Used services and costs are calculated per person-year, and all costs are

145 presented in euros $(€)$.

$146 \mathrm{HRQoL}$ was assessed via the 15D questionnaire ${ }^{28}$ at baseline and after three, six and 12

147 months. 15D has fifteen items, each having five answer options. The questionnaire was sent

148 to the participants prior to the assessor's home visits. Each person completed the

149 questionnaire by themselves or with the help of their relatives. If needed, the research

150 physiotherapist or nurse helped the participant to complete the form. A weighted HRQoL

151 index ranging from one (full health) to zero (death) was calculated.

152 Cost-effectiveness of the intervention was assessed with incremental cost-effectiveness ratio,

153 based on the 12-month data of total costs $(€)$ of used healthcare and social services and 154 changes in QALYs.

155 At baseline, background information on marital status, living arrangements, illnesses and 156 medication were gathered by interview and were completed by using electronic medical 157 records. 


\section{Intervention}

Participants in the physical-exercise group performed physiotherapist-supervised homebased physical exercises for 60 minutes, twice a week over 12 months. Exercises included 10 minutes of warm-up, 30-40 minutes of strength exercises mainly for the lower limbs, and 10 minutes of balance, flexibility and functional exercises combined with other exercises. The physiotherapists tailored the exercises according to the participants' health status and condition. The main strength and balance exercises were based on the exercises of the Otago program..$^{29,30}$ Ankle weights, weight vests, dumbbells, kettlebells and elastic bands were used to add resistance. Over the 12 months, exercise periods of power, force and endurance were cycled every eight to 12 weeks.

Therapists used dynamic, static and dual-task exercises, different surfaces at home and various types of equipment to add difficulty to the balance exercises. The goal was to include balance exercises as part of the functional exercises used to aid everyday tasks that a person needs to be able to live independently at home. Flexibility exercises were predominantly targeted at the larger joints to improve range of motion. Physiotherapists also gave counseling on nutrition. The participants could use all healthcare or social services they may have needed over 24 months. The usual-care group continued to live their lives as usual, without restrictions.

\section{Statistical analysis}

Concerning power calculations in connection with frail patients, there were no previous data on the duration of living at home. Therefore, we used data on Finnish patients with hip fractures in the PERFECT (PERFormance, Effectiveness and Cost of Treatment episodes) study, ${ }^{31}$ in which data are available on the proportion of patients living at home one year after 
the fracture. To detect a difference $(\alpha=0.05$, power=80\%) from the hypothesized difference of 180 days between the physical-exercise and usual-care groups, a sample size of 91 persons in each group would be needed. To allow for discontinuation (estimated as $15 \%$ ) and death (20\%) of participants during 24 months, our targeted sample size was 300 participants.

Descriptive statistics are presented as means with SDs or as counts with percentages. The primary outcome (days spent at home), and outpatient and inpatient visits to healthcare and social services were analyzed by using Poisson's model and reported as days and incidence rate ratios (IRRs) with 95\% confidence intervals (Cls). Repeated measures in HRQoL between the groups were analyzed by using mixed-effects models, with unstructured covariance structure (Kenward-Roger method to the calculate degrees of freedom). Fixed effects were group, time, and group-time interactions. Cost analyses were performed using a generalized linear regression model with log link and gamma variance functions. The variance function was selected based on the Park test and Akaike's information criterion.

Cost-utility analyses in relation to QALYs were based on areas under the curve of 15D scores from baseline to the last measurement point. All participants who completed the baseline assessment and had at least one other measurement point were included in the analyses of HRQoL and QALYs. All costs were presented per person-year. The cost-effectiveness of homebased physical exercise was compared with usual care by using the incremental costeffectiveness ratio (ICER). The bootstrapping technique was used in connection with incremental cost-effectiveness planes for costs and QALYs (5,000 replicates). The normality of variables was evaluated graphically and by using the Shapiro-Wilk W-test. Statistical analyses were performed by using the Stata 16.0, StataCorp LP (College Station, TX, USA) statistical package. 
Eligibility was tested in 520 persons and recruitment was completed when the targeted 300 persons were reached. After randomization, one person in the usual-care group withdrew his/her consent to participate and declined the use of his/her data. The flowchart is shown in Figure 1. The mean age of the 299 participants was 82.5 years, $75 \%$ were female, $39 \%$ were frail, $61 \%$ were pre-frail, and 58\% lived alone. Baseline characteristics are shown in Table 1.

\section{Primary outcome}

At 24 months, the primary outcome was analyzed in 299 participants. Over the 24 months (730 days) the mean number of days spent at home was $659(95 \% \mathrm{Cl} 635$ to 683$)$ in the exercise group and $638(95 \% \mathrm{Cl} 611$ to 665$)$ in the usual-care group (IRR 1.03 [95\% $\mathrm{Cl} 0.98$ to 1.09], $p=0.26)$. In addition, there was no difference in the days at home between the exercise and usual care groups by the frailty subgroups, for frail IRR 1.04 (0.96 to 1.12) and pre-frail IRR 1.03 (0.96 to 1.11). Eleven persons (7\%) in the exercise group and 13 persons (9\%) in usual care were permanently placed in nursing homes $(p=0.66)$. In the exercise group 18 persons and in usual care 19 persons died within the 24-month study period; of these five and 10 persons died during the first 12 months, respectively (Figure 1). Sixty-one persons (41\%) in the exercise group and 57 persons (38\%) in usual care lived at home for the full 730 days without temporary inpatient care.

\section{Secondary outcomes}

224 Data on utilization of healthcare and social services (outpatient visits and inpatient days) and related costs are presented in Table 2. Mean total costs incurred by healthcare and social services per person-year during the first 12 months were 1.60 -fold ( $95 \% \mathrm{Cl} 1.23$ to 1.98 ) in 
the exercise group $(33,839 €)$ when compared with those in usual care $(21,115 €)$. Over the 24-month period, mean costs per person-year were 1.23 -fold (95\% $\mathrm{Cl} 0.95$ to 1.50 ) in the exercise group $(29,428 €)$ compared with those in usual care $(23,961 €)$. Over the 24 months, in the exercise frail subgroup the mean costs were 1.02 times ( $95 \% \mathrm{Cl} 0.75$ to 1.38 ) higher $[32,507 €(S E 3,625)$ vs. 31,979€ (SE 3,597)] and in the exercise pre-frail subgroup 1.46 times (95\% Cl 1.03 to 2.06$)$ higher $[27,431 €(S E 3,348)$ vs. $18,851 €$ (SE 2,301)] when compared with the corresponding subgroups in the usual care.

We analyzed the effects of the intervention on HRQoL over 12 months, covering $96 \%(n=144)$ of the participants in the exercise group and $95 \%(n=141)$ of those in usual care. In the usualcare group the mean HRQoL score decreased significantly by 0.037 compared with the exercise group, which maintained the baseline level ( $p$ for group $<0.001$, time $p=0.002$, interaction $p=0.002$ ) (Figure 2). The difference in HRQoL is also seen in the subgroups of frail ( $p$ for group 0.002 , time $p=0.001$, interaction $p=0.084$ ) and pre-frail ( $p$ for group 0.064 , time $p=0.078$, interaction $p=0.004$ ) (Figure 2 ).

When HRQoL was converted to QALYs, the exercise group gained 0.040 QALYs more compared with the usual-care group over the 12 months (mean QALYs 0.723 and 0.683 , respectively). In the incremental cost-effectiveness ratio plane, all participants lay in the northeast quadrant, implying that the intervention was more effective but more costly than usual care.

The intervention group completed in total 12,981 physical-exercise sessions and the mean number of sessions per participant was 87 , median 96 , with range of $3-104$. Of the participants $58 \%$ reported exercise-related mild transient muscle soreness, and $71 \%$ reported mild joint pain at some point during the year; 17 falls occurred during exercise sessions, with 
one fall leading to an injury that needed medical care, and 18 persons took nitroglycerin during or after one exercise session. On five occasions, a participant needed acute medical care because of health problems at the time of the physiotherapist visit.

\section{DISCUSSION}

The primary aim of this trial was to explore the effects of a 12-month supervised home-based physical-exercise regimen on the number of days lived at home among pre-frail and frail persons within 24 months. Our intervention did not significantly increase the number of days spent at home compared with usual care.

In previous studies, interventions including exercise training have not decreased the rates of permanent nursing-home placements or acute hospitalizations in community-living frail persons, ${ }^{32}$ or hospitalizations in persons living in nursing homes. ${ }^{33}$ Frail persons are at a higher risk of nursing-home placement than pre-frail ones, and pre-frail persons are at a higher risk when compared with robust ones. ${ }^{34}$ In our trial, a majority of participants were pre-frail (61\%), which might reflect the low number of persons transferred to nursing homes. In addition, there was no difference between the groups in the 24-month mortality rate.

Our secondary aim was to study if costs of healthcare and social services can be reduced by way of the physical-exercise regimen. Frailty is associated with higher rates of hospitalization, ${ }^{35}$ longer hospital stays ${ }^{13}$ and higher healthcare $\operatorname{costs}^{36}$ and clinical guidelines recommend physical exercise as a treatment option for frailty. ${ }^{3}$ Over intervention year the costs per person-year in the exercise group were found to be increased vs. usual care, but the difference decreased over the next 12 months., The total costs over 24 months in the frail subgroup were the same between the exercise and usual-care, but the pre-frail exercise subgroup remained higher vs. usual care. Thus, targeting the intervention to those who are 
frail seems to be the most cost-beneficial. In another study, an intervention with physical exercise was considered as the most likely cost saving among the very frai ${ }^{37}$.

Over the 12-month intervention period, those in the exercise group maintained their HRQoL score at the baseline level, whereas the score in the usual-care group deteriorated by 0.037 . This deterioration can be considered as considerable and clinically meaningful. Regarding the 15D measure, a minimal important change has been proposed to be $+/-0.015$ and a change of +/-0.035 can be considered large. ${ }^{38}$ In healthcare interventions, physical exercise has had an inconclusive effect on HRQoL in pre-frail and frail older adults ${ }^{20}$ and HRQoL did not change in previous short-term home-based training studies..$^{39,40}$

From the-cost-effectiveness point of view, exercise was more effective and more costly within the first 12 months, as the exercise group gained 0.04 QALYs more and the costs were 1.60fold greater compared with the usual-care group. Our findings are in line with those in the LIFE study, where sedentary older persons who participated in physical activity with a goal of 150 minutes per week accrued 0.047 QALYs over 2.6 years compared with the group that received health education. ${ }^{41}$ In comparison with our study, not all the participants in the LIFE study ${ }^{41}$ were frail at the beginning, as it was not among the inclusion criteria.

As a strength of our trial, it had a rigorous randomized design. All 299 participants were followed using register data for 24 months, or until their death. We retrieved data from medical records and were able to identify every contact between a patient and healthcare and homecare professionals, which took place in the services provided by the district. We were also able to retrieve information on visits to private outpatient healthcare services from the social insurance registers, although the number of reimbursed visits was low. As a limitation of our trial, we assessed HRQoL and QALYs only for the first 12 months (as 
planned). In addition, during our study period (2014-2018), the policies in the district changed: resources were targeted more to services at home such as homecare, and the number of nursing homes was reduced. In 2018, the district had the lowest national percentage of older persons in nursing homes. ${ }^{42}$ This development may also have had an impact on the total number of persons assigned to long-term care in our study. A longer follow-up time or including only frail participants might have had more impact on the between-group difference in the days at home. In future trials, finding a way to decrease the costs of the supervised home-based exercise intervention, e.g. with the help of remote technologies, or combining exercise to homecare visits could be beneficial.

\section{CONCLUSIONS AND IMPLICATIONS}

Contrary to our hypothesis, the 12 months' physiotherapist-supervised home-based physical exercise in frail and pre-frail persons had no effect on the number of days spent at home. The exercise investment was costly, but the costs were gained back in decreased utilization of healthcare and social services in the exercise frail subgroup over 24 months. Physical exercise had a considerable clinical effect on HRQoL and QALYs when compared with the usual care. The authors declare no conflicts of interest. 


\section{References}

1 Clegg A, Young J, Illiffe S, et al. Frailty in elderly people. Lancet 2013;381:752-762.

2 Morley JE, Vellas B, Abellan van Kan G, et al. Frailty consensus: A call to action. J Am Med Dir Assoc 2013;14:392-397.

3 Dent E, Morley JE, Cruz-Jentoft AJ, et al. Physical frailty: ICFSR international clinical practice guidelines for identification and management. J Nutr Health Aging 2019;23:771787.

4 Markle-Reid M, Browne G. Conceptualizations of frailty in relation to older adults. J Adv Nurs 2003;44:56-68.

5 Hoogendijk EO, Afialo J, Ensrud KE, et al. Frailty: implications for clinical practice and public health. Lancet 2019;394:1365-1375.

6 Santos-Eggiman B, Cuénoud P, Spagnoli J, Junod J. Prevalence of frailty in middle-aged and older community-dwelling Europeans living in 10 countries. J Gerontol A Biol Sci Med Sc 2009;64A:675-681.

7 Collard RM, Boter H, Schoevers RA, Oude Voshaar RC. Prevalence of frailty in communitydwelling older persons: A systematic review. J Am Geriatr Soc 2012:60:1487-1492.

8 Fried LP, Tangen CM, Walston J, et al. Frailty in older adults: evidence for a phenotype. J Gerontol A Biol Sci Med Sci 2001;56:146-156.

9 Ilinca S, Calciolari S. The patterns of health care utilization by elderly Europeans: Frailty and its implications for health systems. Health Serv Res 2015;50:305-320.

10 Bandeen-Roche K, Seplaki CL, Huang J, et al. Frailty in older adults: A nationally representative profile in the United States. J Gerontol A Biol Sci Med Sci 2015;70:14271434.

11 Zhu Y, Liu Z, Wang Y, et al. Agreement between the frailty index and phenotype and their associations with falls and overnight hospitalizations. Arch Gerontol Geriatr 2016;66:161165.

12 Chang S-F, Lin H-C, Cheng C-L. The relationship of frailty and hospitalization among older people: Evidence from a meta-analysis. J Nurs Scholarsh 2018;50:383-391.

13 Khandelwal D, Goel A, Kumar U, et al. Frailty associated with longer hospital stay and increased mortality in hospitalized older patients. J Nutr Health Aging 2012;16:732-735.

14 Kojima G, lliffe S, Jivraj S, Walters K. Association between frailty and quality of life among community-dwelling older people: a systematic review and meta-analysis. J Epidemiol Community Health 2016;70:716-721.

15 Chang S-F, Lin P-L. Frail phenotype and mortality prediction: A systematic review and meta-analysis of prospective cohort studies. Int J Nurs Stud 2015;52:1362-1374.

16 Kojima G. Frailty as a predictor of nursing home placement among community-dwelling older adults: A systematic review and meta-analysis. J Geriatr Phys Ther 2018;41:42-48. 
17 Hajek A, Bock J-O, Saum K-U, et al. Frailty and healthcare costs - longitudinal results of a prospective cohort study. Age Ageing 2018;47:233-241.

18 Ensrud KE, Kats AM, Shousboe JT, et al. Frailty phenotype and healthcare costs and utilization in older women. J Am Geriatr Soc 2018;66:1276-1283.

19 Theou O, Stathokostas L, Roland KP, et al. The effectiveness of exercise interventions for the management of frailty: a systematic review. J Aging Res 2011: 569194. doi: $10.4061 / 2011 / 569194$

20 van Rijckvorsel-Scheele J, Willems RCWJ, Roelofs PDDM, et al. Effects of health care interventions on quality of life among frail elderly: a systematized review. Clin Interv Aging 2019:14;643-658.

21 Soukkio P, Suikkanen S, Kääriä S, et al. Effects of 12-month home-based physiotherapy on duration of living at home and functional capacity among older persons with signs of frailty or with a recent hip fracture - protocol of a randomized controlled trial (HIPFRA study). BMC Geriatr 2018;18:232. doi: 10.1186/s12877-018-0916-y

22 Morley JE, Malmstrom TK, Miller DK. A simple frailty questionnaire (FRAIL) predicts outcomes in middle aged african americans. J Nutr Health Aging 2012;16:601-608.

23 Suikkanen S, Soukkio P, Pitkälä K, et al. Older persons with signs of frailty in a homebased physical exercise intervention: baseline characteristics of an RCT. Aging Clin Exp Res 2019;31:1419-1427.

24 Guralnik J, Simonsick E, Ferrucci L, et al. A short physical performance battery assessing lower extremity function: association with self-reported disability and prediction of mortality and nursing home admission. J Gerontol 1994;49:85-94.

25 Guralnik JM, Ferrucci L, Pieper CF, et al. Lower extremity function and subsequent disability: Consistency across studies, predictive models, and value of gait speed alone compared with the Short Physical Performance Battery. J Gerontol Med Sci 2000;55:M221231.

26 Folstein MF, Folstein SE, McHugh PR. "Mini-mental state". A practical method for grading the cognitive state of patients for the clinician. J Psychiatr Res 1975;12:189-198.

27 Kapiainen S, Väisänen A, Haula T. [Unit costs of health and social care in Finland 2011; in Finnish]. Finnish Institute for Health and Welfare (THL); 2014. Report No. 3/2014. https://www.julkari.fi/handle/10024/114683. Accessed February 19, 2020.

28 Sintonen H. The 15D-measure of health-related quality of life. I. Reliability, validity and sensitivity of its health state descriptive system. National Centre for Health Program Evaluation, Working Paper 41, Melbourne, Australia, 1994. pdfs.semanticscholar.org/64d2/f291b61e8f7ca83cf890736cf52d2ead0a71.pdf. Accessed May 2, 2020.

29 Accident Compensation Corporation (ACC). OTAGO exercise programme. To prevent falls in older adults. 2003. https://www.livestronger.org.nz/assets/Uploads/acc1162-otagoexercise-manual.pdf. Accessed May 13, 2020. 
30 Thomas S, Mackintosh S, Halbert J. Does the 'Otago exercise programme' reduce mortality and falls in older adults? : a systematic review and meta-analysis. Age Ageing 2010;39:681-687.

31 Sund $R$, Juntunen $M$, Lüthje $P$, et al. Monitoring the performance of hip fracture treatment in Finland. Ann Med 2011;43 Suppl 1:39-46.

32 Cameron ID, Fairhall N, Langron C, et al. A multifactorial interdisciplinary intervention reduces frailty in older people: randomized trial. BMC Med 2013;11:65. doi: 10.1186/17417015-11-65.

33 Arrieta H, Rezola-Pardo C, Gil SM, et al. Effects of multicomponent exercise on frailty in long-term nursing homes: a randomized controlled trial. J Am Geriatr Soc 2019;67:11451151. doi:10.1111/jgs.15824.

34 Kojima G. Increased healthcare costs associated with frailty among community-dwelling older people: A systematic review and meta-analysis. Arch Gerontol Geriatr 2019;84. doi: 10.1016/j.archger.2019.06.003.

$35 \mathrm{Kim}$ DH, Glynn RJ, Avorn J, et al. Validation of a claims-based frailty index against physical performance and adverse health outcomes in the health and retirement study. Gerontol $A$ Biol Sci Med Sci 2019;74:1271-1276.

36 Bock JO, Köning $\mathrm{HH}$, Brenner $\mathrm{H}$, et al. Associations of frailty with health care costs results of the ESTHER cohort study. BMC Health Serv Res 2016;16:128. doi: 10.1186/s12913016-1360-3.

37 Fairhall N, Sherrington C, Kurrle SE, et al. Economic evaluation of a multifactorial, interdisciplinary intervention versus usual care to reduce frailty in frail older people. J Am Med Dir Assoc 2015;15:41-48.

38 Alanne S, Roine RP, Räsänen $\mathrm{P}$, et al. Estimating the minimum important change in the 15D scores. Qual Life Res 2015;24:599-606.

39 Clegg A, Barber S, Young J, et al. The home-based older people's exercise (HOPE) trial: a pilot randomized controlled trial of home-based exercise intervention for older people with frailty. Age Ageing 2014;43:687-695.

40 Kapan A, Winzer E, Haider S et al. Impact of a lay-led home-based intervention programme on quality of life in community-dwelling pre-frail and frail older adults: a randomized controlled trial. BMC Geriatr 2017;17:154. doi: 10.1186/s12877-017-0548-7.

41 Groessl EJ, Kaplan RM, Castro Sweet CM, et al. Cost-effectiveness of the LIFE physical activity intervention for older adults at risk for mobility disability. J Gerontol A Biol Sci Med Sci 2016;71:656-662.

42 Finnish Institute for Health and Welfare (THL). [Home care and nursing homes for older persons in 2018; in Finnish with appendices in English]. http://www.julkari.fi/handle/10024/138808. Accessed April 15, 2020. 


\section{$429 \quad$ Figure Legends}

430 Figure 1. Flowchart of the randomized controlled trial; number of participants.

431 Figure 2. Health-related quality of life (HRQoL) in the physical-exercise group and the usual-care groups, in all participants and in subpopulations of pre-frail and frail over the 12-month intervention

433 period. Means with whiskers representing $95 \% \mathrm{Cl}$.

434

435

436 
Table 1. Baseline characteristics of participants in the physical-exercise and usual-care groups.

Means (SD) or proportions (\%).

\begin{tabular}{|c|c|c|c|}
\hline Characteristics & $\begin{array}{c}\text { Physical exercise } \\
(n=150)\end{array}$ & $\begin{array}{c}\text { Usual care } \\
(n=149)\end{array}$ & $\begin{array}{c}\mathrm{p}- \\
\text { value }\end{array}$ \\
\hline Age, mean (SD) & $82.2(6.3)$ & $82.7(6.3)$ & 0.44 \\
\hline Women, n (\%) & $114(76)$ & $110(74)$ & 0.67 \\
\hline Body Mass Index $\left(\mathrm{kg} / \mathrm{m}^{2}\right)$, mean (SD) & $28.4(5.5)$ & $28.6(6.1)$ & 0.78 \\
\hline $\mathrm{MMSE}^{*}$, mean (SD) & $24.2(3.1)$ & $24.6(3.2)$ & 0.39 \\
\hline Marital status, n (\%) & & & 0.19 \\
\hline Married/in a relationship & $56(37)$ & $62(42)$ & \\
\hline Single/divorced & $19(13)$ & $27(18)$ & \\
\hline Widowed & $75(50)$ & $60(40)$ & \\
\hline Living, n (\%) & & & 0.13 \\
\hline Alone & $88(59)$ & $86(58)$ & \\
\hline With spouse & $47(31)$ & $57(38)$ & \\
\hline With another person (other than spouse) & $15(10)$ & $6(4)$ & \\
\hline Home care at least once a week, n (\%) & $27(18)$ & $34(23)$ & 0.30 \\
\hline Education $<9$ years, $\mathrm{n}(\%)$ & $99(66)$ & $90(60)$ & 0.32 \\
\hline Severity of frailty & & & 0.94 \\
\hline Pre-frail, $1-2$ of the 5 criteria, $n(\%)$ & $91(61)$ & $91(61)$ & \\
\hline Frail, $3-5$ of the 5 criteria, $n(\%)$ & $59(39)$ & $58(39)$ & \\
\hline \multicolumn{4}{|l|}{ Physician-diagnosed diseases or disorders, n (\%) } \\
\hline Cardiovascular diseases ${ }^{\dagger}$ & $76(52)$ & $91(61)$ & 0.070 \\
\hline Hypertension & $110(73)$ & $110(74)$ & 0.92 \\
\hline Stroke or TIA & $37(25)$ & $33(22)$ & 0.61 \\
\hline Diabetes & $31(21)$ & $45(30)$ & 0.059 \\
\hline Musculoskeletal diseases & $129(86)$ & $124(83)$ & 0.51 \\
\hline $\mathrm{COPD}^{\S}$ or asthma & $16(11)$ & $20(13)$ & 0.46 \\
\hline Dementia & $19(13)$ & $22(15)$ & 0.60 \\
\hline Number of regular medications, mean (SD) & $6.7(3.2)$ & $7.0(3.1)$ & 0.43 \\
\hline Health-Related Quality-of-Life, 15D, mean (SD) & $0.719(0.084)$ & $0.705(0.097)$ & 0.19 \\
\hline
\end{tabular}

439

440

441

442

443

444

445

446

447

* Mini-Mental State Examination

$\dagger$ includes coronary heart disease, angina pectoris, myocardial infarction, heart failure

¥ Transient Ischemic Attack

$\S$ Chronic Obstructive Pulmonary Disease 
Table 2. Use of healthcare and social services (outpatient visits to healthcare, inpatient days in hospitals and nursing homes, and home care visits) and their costs $(€)$ per person-year in the physical-exercise and usual-care groups over 0-12 months and 0-24 months.

\begin{tabular}{|c|c|c|c|c|c|c|}
\hline \multirow[b]{3}{*}{$0-12$ months } & \multicolumn{3}{|c|}{ Healthcare and social services, visits or days per person-year } & \multicolumn{3}{|c|}{ Healthcare and social services, costs per person-year } \\
\hline & $\begin{array}{c}\text { Usual care } \\
(n=149)\end{array}$ & $\begin{array}{c}\text { Physical exercise } \\
(n=150)\end{array}$ & & $\begin{array}{c}\text { Usual care } \\
(n=149)\end{array}$ & $\begin{array}{c}\text { Physical exercise } \\
(n=150)\end{array}$ & \multirow[b]{2}{*}{$\begin{array}{c}\text { Mean ratio }^{\ddagger} \\
(95 \% \mathrm{Cl})\end{array}$} \\
\hline & Mean (SE) & Mean (SE) & $\operatorname{IRR}^{\dagger}(95 \% \mathrm{Cl})$ & Mean, $€(S E)$ & Mean, $€(\mathrm{SE})$ & \\
\hline Home care, visits & $160.5(24.8)$ & $117.2(19.3)$ & $0.73(0.47$ to 1.14$)$ & $7187(1093)$ & $5269(866)$ & $0.73(0.41$ to 1.05$)$ \\
\hline \multicolumn{7}{|l|}{ Primary care } \\
\hline General practitioner, visits & $9.57(0.70)$ & $9.41(0.74)$ & $0.98(0.80$ to 1.21$)$ & $1234(114)$ & $1201(114)$ & $0.97(0.72$ to 1.23$)$ \\
\hline Nurse, visits & $19.56(1.60)$ & $17.19(1.41)$ & $0.88(0.70$ to 1.10$)$ & $1023(83)$ & $907(76)$ & 0.89 (0.69 to 1.09$)$ \\
\hline Rehabilitation*, visits & $8.06(1.09)$ & $91.54(1.50)$ & 11.35 (8.69 to 14.82$)$ & 1407 (187) & $8153(145)$ & 5.79 (4.28 to 7.30$)$ \\
\hline Primary-care ward, days & $8.03(2.74)$ & $6.29(1.72)$ & $0.78(0.33$ to 1.85$)$ & $2750(867)$ & $2468(708)$ & $0.90(0.15$ to 1.64$)$ \\
\hline Home healthcare, visits & $2.98(0.50)$ & $2.99(0.52)$ & 1.00 (0.63 to 1.61$)$ & $373(63)$ & $389(69)$ & $1.04(0.54$ to 1.54$)$ \\
\hline \multicolumn{7}{|l|}{ Specialized medical care } \\
\hline Physician, visits & $2.50(0.28)$ & $2.29(0.28)$ & 0.92 (0.66 to 1.26$)$ & $694(77)$ & $668(82)$ & 0.96 (0.65 to 1.27$)$ \\
\hline Nurse, visits & $1.30(0.32)$ & $1.38(0.34)$ & 1.07 (0.54 to 2.10$)$ & $66(16)$ & $72(18)$ & 1.11 (0.38 to 1.83$)$ \\
\hline Emergency department, visits & $1.73(0.23)$ & $1.84(0.23)$ & 1.06 (0.74 to 1.52$)$ & $590(80)$ & $683(116)$ & 1.16 (0.66 to 1.65$)$ \\
\hline Hospital wards, days & $3.26(0.49)$ & $4.57(0.80)$ & $1.40(0.89$ to 2.21$)$ & $3644(831)$ & $4931(1175)$ & 1.35 (0.48 to 2.22$)$ \\
\hline Nursing home, days & $3.04(1.15)$ & $5.20(2.09)$ & 1.71 (0.58 to 5.04$)$ & $777(360)$ & $946(372)$ & 1.22 (0.24 to 2.67$)$ \\
\hline Total costs & & & & 21151 (2 185) & 33839 (2 167) & 1.60 (1.23 to 1.98$)$ \\
\hline \multicolumn{7}{|l|}{$0-24$ months } \\
\hline Home care, visits & $185.2(27.1)$ & $141.2(22.6)$ & 0.76 (0.50 to 1.17$)$ & $8268(1162)$ & $6475(1000)$ & $0.78(0.47$ to 1.10$)$ \\
\hline \multicolumn{7}{|l|}{ Primary care } \\
\hline General practitioner, visits & $10.65(0.68)$ & $9.82(0.70)$ & $0.92(0.77$ to 1.11$)$ & 1387 (112) & $1289(113)$ & $0.93(0.71$ to 1.15$)$ \\
\hline Nurse, visits & $20.53(1.60)$ & $18.32(1.31)$ & 0.89 (0.72 to 1.10$)$ & $1067(81)$ & $963(72)$ & 0.90 (0.71 to 1.09$)$ \\
\hline Rehabilitation*, visits & $7.78(0.84)$ & $50.34(1.07)$ & 6.47 (5.21 to 8.04$)$ & $1347(152)$ & $4847(155)$ & 3.60 (2.78 to 4.42$)$ \\
\hline Primary-care ward, days & $9.70(2.60)$ & $6.56(1.47)$ & $0.68(0.34$ to 1.34$)$ & 3378 (834) & $2880(712)$ & 0.85 (0.26 to 1.44$)$ \\
\hline Home healthcare, visits & $3.06(0.41)$ & $3.19(0.45)$ & $1.04(0.71$ to 1.53$)$ & $400(56)$ & $427(64)$ & 1.07 (0.64 to 1.49$)$ \\
\hline \multicolumn{7}{|l|}{ Specialized medical care } \\
\hline Physician, visits & $2.40(0.23)$ & $2.35(0.25)$ & $0.98(0.74$ to 1.30$)$ & $669(65)$ & $706(77)$ & $1.06(0.76$ to 1.35$)$ \\
\hline Nurse, visits & $1.37(0.23)$ & $1.53(0.32)$ & 1.12 (0.66 to 1.90$)$ & $71(12)$ & $82(17)$ & $1.16(0.55$ to 1.77$)$ \\
\hline Emergency department, visits & $1.53(0.18)$ & $1.81(0.19)$ & 1.18 (0.87 to 1.61$)$ & $578(72)$ & $724(113)$ & 1.25 (0.76 to 1.75$)$ \\
\hline Hospital wards, days & $3.20(0.41)$ & $4.22(0.58)$ & 1.32 (0.91 to 1.91$)$ & 3956 (819) & 5064 (1137) & 1.28 (0.53 to 2.03$)$ \\
\hline Nursing home, days & $7.14(1.99)$ & $6.48(2.44)$ & 0.91 (0.36 to 2.27$)$ & $1554(460)$ & $1240(431)$ & $0.80(0.09$ to 1.51$)$ \\
\hline Total costs & & & & 23961 (2 198) & 29428 (2 282) & 1.23 (0.95 to 1.50$)$ \\
\hline
\end{tabular}

*including physiotherapy, occupational therapy, speech therapy and trial intervention (physiotherapist-supervised home-based physical exercise)

†Incidence Rate Ratio, the physical-exercise group over the usual-care group, $\ddagger$ mean ratio, the physical-exercise group over the usual-care group 


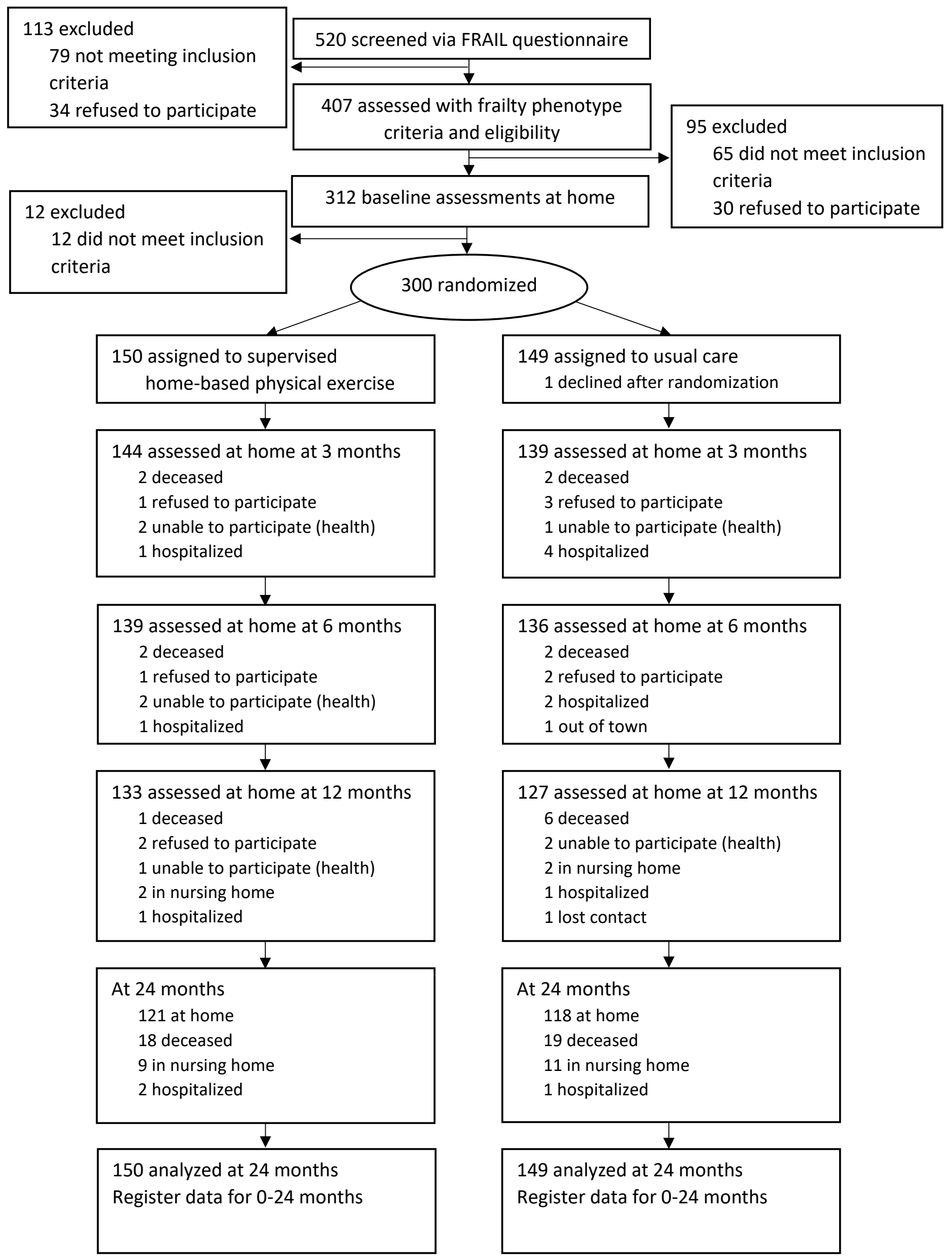

Figure 1. Flowchart of the randomized controlled trial; number of participants. 

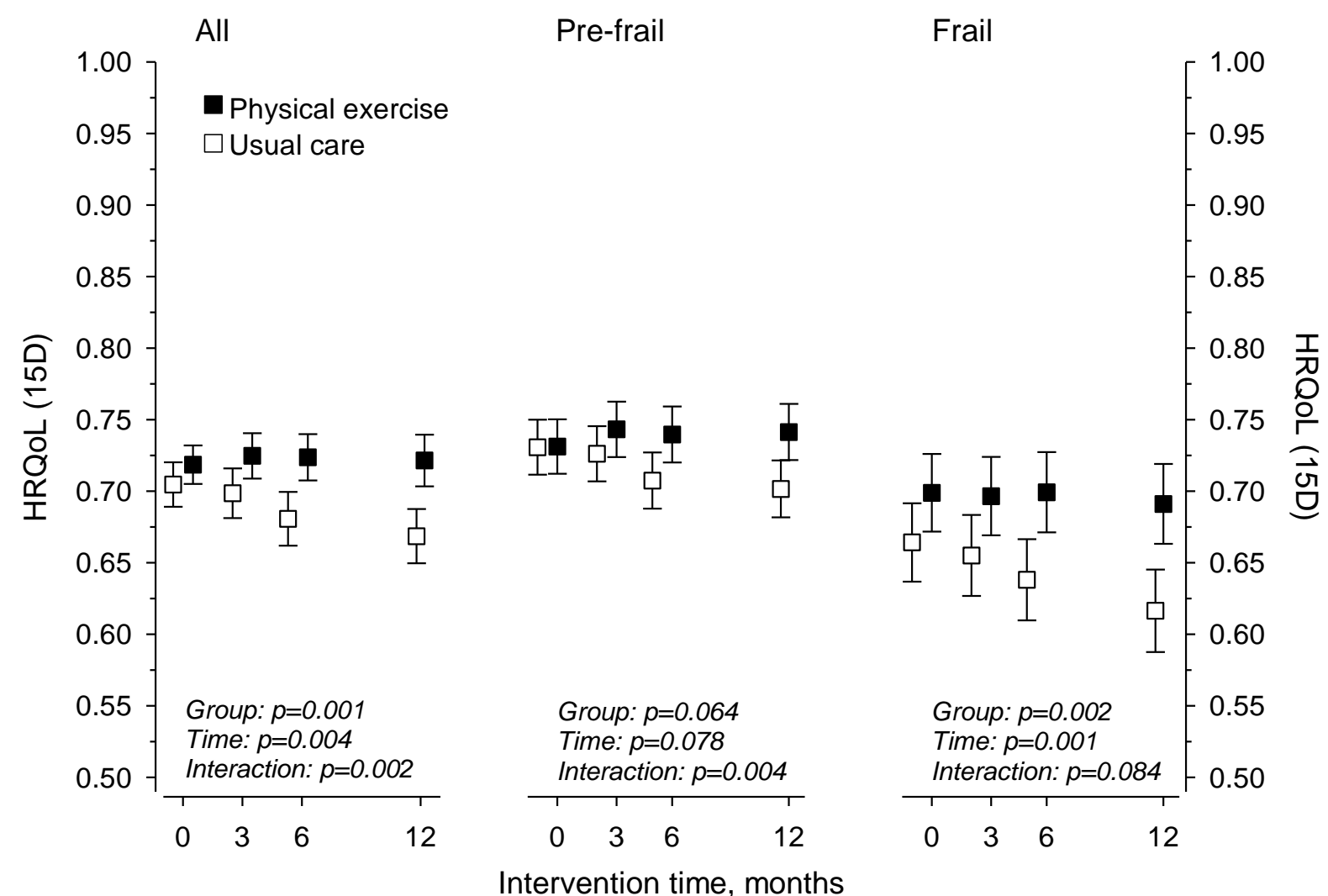

Figure 2. Health-related quality of life (HRQoL) in the physical-exercise group and the usual-care groups, in all participants and in subpopulations of pre-frail and frail over the 12-month intervention period. Means with whiskers representing $95 \% \mathrm{Cl}$. 